\title{
Ensinar e aprender Língua Portuguesa nos anos finais do ensino fundamental
}

(Universidade de São Paulo, São Paulo, SP)
RESUMO: Este artigo compartilha a análise dos documentos curriculares de Língua Portuguesa de seis estados (AC, AL, MT, PR, PE, SP). Inicialmente, traça os fundamentos teóricos que sustentam os documentos curriculares, em seguida discute as implicações de assumir o texto como unidade de ensino (recorrente nos seis documentos) e o tratamento dado aos gêneros textuais, e, por fim, faz considerações a respeito das práticas de linguagem que estruturam a organização dos conteúdos: a oralidade, a de leitura, a produção de textos e a análise linguística. As reflexões são permeadas pelo diálogo com 0 texto na sala de aula - obra emblemática da renovação do ensino de Língua Portuguesa - e com os Parâmetros Curriculares Nacionais (1998), que ajudam na busca de respostas para a seguinte pergunta: Quais mudanças são notáveis no ensino e aprendizagem de Língua Portuguesa nos últimos 30 anos?

PalaVras-chave: Currículo. Língua Portuguesa. Ensino. 


\section{APRESENTAÇÃo}

As reflexões expressas neste artigo sustentam-se na experiência pessoal como formadora de professores, elaboradora de propostas curriculares e, particularmente, como pesquisadora do Projeto "Currículos para os anos finais do ensino fundamental: concepções, modos de implantação, usos”, que buscou descrever e analisar as políticas curriculares para os anos finais do ensino fundamental dos estados brasileiros e do Distrito Federal. As informações aqui reunidas referem-se, particularmente, à segunda etapa do projeto $^{1}$, em que foram analisados os documentos curriculares de cada um dos componentes curriculares de seis estados ( $A C, A L, M T, P R, P E, S P$ ), neste caso específico, Língua Portuguesa.

Para compartilhar os dados analisados, inicialmente traçaremos, em linhas gerais, os fundamentos teóricos que sustentam os documentos curriculares; as implicações, para o currículo de Língua Portuguesa, de assumir o texto como unidade de ensino - recorrente nos seis documentos; o tratamento dado aos gêneros textuais; e, por fim, algumas considerações a respeito das práticas de linguagem que estruturam a organização dos conteúdos desse componente curricular: a oralidade, a de leitura, a produção de textos e a análise linguística.

Permeiam estas reflexões um diálogo com O TEXTO NA SALA DE AULA² - obra emblemática da renovação do ensino de Língua Portuguesa - e com os Parâmetros Curriculares Nacionais (1998), diretrizes elaboradas pelo governo federal que orientam a educação desde sua publicação. Quais mudanças são notáveis no ensino e aprendizagem de Língua Portuguesa nos últimos 30 anos?

No Estudo 1, a pesquisa compara o levantamento de documentos curriculares de estados e municípios feito por Sampaio et al. (2010) com o levantamento realizado ao longo de 2014. 0 Estudo 2 analisa os documentos curriculares norteado por duas perguntas de pesquisa: a) Quais são as concepções que orientam os documentos curriculares para os anos finais do ensino fundamental dos estados brasileiros e do Distrito Federal? e b) Como são abordados os conteúdos dos componentes curriculares?.

Organizado por João Wanderley Geraldi, 0 texto na sala de aula é uma coletânea de 12 artigos escritos por ele e mais sete renomados autores. Em 1984, a primeira edição da obra foi publicada pela Assoeste, uma editora de Cascavel/PR; a partir de 1997, passa a ser publicada pela editora Ática de São Paulo. 


\section{FUndAMENTOS TEÓRICOS}

Embora não sejam explicitados na maioria dos documentos analisados (AC, AL, MT, PR, PE, SP), é possível depreender que são orientados por uma perspectiva sócio-histórica, com base sobretudo nas ideias de Vygotsky e em uma teoria da enunciação de inspiração bakhtiniana, que entende a linguagem como espaço de interlocução, de atividade sociointeracional:

- a unidade de análise é o texto com seus temas, formas de acabamento (composição, estilo);

- o texto só ganha significado a partir de sua circulação em situações concretas de produção (enunciação);

- a enunciação e, por decorrência, o texto são sempre dialógicos, polissêmicos;

- a relação entre enunciador e destinatário(s) implica a definição de papéis e perspectivas que se multiplicam nos mais variados planos enunciativos da interação.

Ensinar Língua Portuguesa a partir dessa concepção requer que se considerem os aspectos sociais e históricos em que o sujeito está inserido, bem como o contexto de produção do enunciado, uma vez que os seus significados são social e historicamente construídos:

\footnotetext{
No processo de ensino-aprendizagem, é importante ter claro que quanto maior o contato com a linguagem, nas diferentes esferas sociais, mais possibilidades se têm de entender o texto, seus sentidos, suas intenções e visões de mundo. A ação pedagógica referente à linguagem, portanto, precisa pautar-se na interlocução, em atividades planejadas que possibilitem ao aluno a leitura e a produção oral e escrita, bem como a reflexão e o uso da linguagem em diferentes situações. Desse modo, sugere-se um trabalho pedagógico que priorize as práticas sociais (PARANÁ, 2008, p. 55).
}

A concepção sociointeracionista da linguagem implica conceber a interação verbal como lócus de toda a atividade linguística, já que a língua e o sujeito se constituem nos processos interativos. Coerente com tal concepção, esperase que as escolas proporcionem a maior diversidade possível de interações de várias instâncias discursivas. São essas experiências que permitirão compreender o caráter particular e singular de cada evento discursivo, orientado tanto pelo texto do locutor como pelas categorias prévias incorporadas pelo interlocutor. Em jogo, encontram-se diferentes sistemas de referências:

\footnotetext{
[...] é pelo processo de internalização do que nos era exterior que nos constituímos como os sujeitos que somos, e, com as palavras de que dispomos, trabalhamos na construção de novas palavras (GERALDI, 1996, p. 67).
} 


\section{O TEXTO COMO UNIDADE DE ENSINO}

Reiterado como uma espécie de mantra, assume-se o texto como unidade de ensino, já que a linguagem se constitui na interação verbal. 0 texto é entendido como a materialização de um discurso, o que exige ir além de observar a aplicação de regras, bem como as regularidades recorrentes nos diferentes tipos e gêneros; implica levar em conta as articulações com a situação enunciativa, isto é, as relações entre os interlocutores, a temática, os recursos estilísticos e expressivos mobilizados, sua adesão ou não a sistemas de referências.

Como o texto, entendido dessa forma tão fluida e instável, converte-se em objeto das práticas de escuta ou de leitura, ou em objeto da prática de produção oral ou escrita, ou ainda da prática de análise linguística? Pouco se fala que trazer o texto para a sala de aula é aceitar o desafio de lidar com um horizonte instável, já que a construção de sentidos é atravessada pelos sujeitos, sendo sempre possível a emergência de sentidos não previstos.

Outro aspecto negligenciado são os critérios que orientam a seleção de textos. Já que o texto é a unidade de ensino, as atividades de compreensão e de produção de texto serão fortemente impactadas pela complexidade estrutural do texto, seu universo temático, sua densidade argumentativa, em função das características do aluno (sua idade, maturidade afetiva e intelectual e 0 nível de escolaridade). A complexidade da seleção lexical (maior ou menor presença de vocábulos de uso comum), a organização sintática (tamanho das frases, ordem direta $x$ indireta, relações de coordenação e subordinação), a temática desenvolvida (relação entre tema e faixa etária, tema e cultura, vulgarização do tema), sua referencialidade (um texto de identificação de objeto é mais simples do que um texto em que se manifeste a percepção subjetiva da realidade), os recursos expressivos explorados (uso de elementos metafóricos, metonímicos, entre outros), bem como as determinações do gênero e da época em que o texto foi produzido projetam interlocutores, demandam mediações de maior ou menor intensidade.

Como orientar a progressão sem estabelecer alguns parâmetros que definam o grau de complexidade dos textos? Como orientar a progressão sem debruçarse com seriedade sobre a construção de um acervo básico que crie alguns parâmetros do que se projeta como autonomia do sujeito?

Apenas na Base Curricular Comum para as Redes Públicas de Ensino de Pernambuco (2008), encontram-se alguns parâmetros para orientar essa escolha: 
No que concerne às atividades de leitura e compreensão, a escolha dos textos constitui uma tarefa das mais decisivas. Na verdade, os textos são a base a partir da qual são feitos os cálculos interpretativos e constituem um dos pontos de apoio que nos autorizam a admitir esta ou aquela compreensão.

Nesta perspectiva, espera-se que se tenha todo o cuidado para que os textos:

- sejam interessantes, adequando-se, na temática e na estruturação linguística, à faixa etária dos alunos;

- apresentem uma temática relevante, estimuladora, e instigante;

- contemplem diferentes universos de referência e, assim, não se restrinjam, por exemplo, a ideias, informações ou temas específicos de uma região;

- contemplem diferentes universos culturais e, dessa forma, incluam, além dos temas próprios do mundo urbano, temas próprios do mundo do campo;

- remetam para os diferentes domínios de produção e divulgação do conhecimento, tais como imprensa, ciência, literatura, arte, política em prosa e em verso e, assim, tenham como suporte o jornal, a revista, o livro de ciências, o livro de literatura, a enciclopédia, o folheto de cordel, o cartaz, entre outros;

- mostrem a diversidade de gêneros de textos que circulam nos diferentes meios sociais, tais como comentários, informações científicas, notícias, trechos de reportagens, trechos de entrevistas, narrativas, crônicas, fábulas, histórias em quadrinhos, tiras, charges, poemas, anúncios, avisos, cartas, convites, declarações, para citar apenas estes;

- sejam representativos de diferentes dialetos (padrão e não padrão; desta e de outras regiões) e de diferentes registros (formal e informal) - com o cuidado para que não se restrinjam a particularidades muito específicas de um determinado lugar ou situação;

- utilizem diferentes recursos visuais e gráficos (imagens, fotos, figuras, e outros sinais, como diferentes tipos, tamanhos, cores e formatos das letras) ou sejam diversificados quanto à sua forma de apresentação gráfica (tabelas, gráficos, mapas e outros similares);

- preservem a unidade de sentido e a relevância do conteúdo, no caso de sofrerem adaptações ou supressões;

- tenham uma extensão compativel com a faixa etária e, principalmente, com o tempo destinado à atividade proposta;

- explicitem seus elementos de contextualização, tais como autoria, suporte, lugar e época de publicação (PERNAMBUCO, 2008, p. 76-77).

Causa alguma estranheza o silêncio em relação à questão tão relevante. 


\section{O TRATAMENTO DADO AOS GÊNEROS TEXTUAIS}

Ao considerar-se o texto como unidade de ensino, é incontornável filiá-lo a um gênero: responde-se a diferentes situações comunicativas, ajustando os textos a certas regularidades que são reconhecidas pelos interlocutores. Essa dimensão discursiva exige ir além da mera descrição das propriedades formais a que cada texto se submente ao ser inscrito em um determinado gênero textual; exige construir uma representação da situação de produção apoiada nos parâmetros de interação social, isto é, identificar o lugar social do enunciador, a finalidade da atividade de linguagem, as relações entre os interlocutores.

É possível abordar a diversidade de gêneros na escola sem organizar uma proposta de ensino-aprendizagem a partir dos gêneros, que os toma como ferramentas para ampliar as capacidades discursivas e linguísticas dos alunos. Porém, se o trabalho com os gêneros assumir um caráter estruturante na elaboração do currículo, é incontornável estabelecer algum critério para o agrupamento dos gêneros que viabilizará a seleção e a progressão ao longo dos diferentes anos da educação básica. Alguns desses critérios podem ser a separação entre gêneros primários e gêneros secundários, proposta por Bakhtin; os aspectos tipológicos (narração, descrição, exposição, argumentação, injunção); as esferas discursivas (literária, acadêmica, jornalística etc.).

Um exemplo claro dessa organização encontra-se no Currículo do Estado de São Paulo: Linguagens, códigos e suas tecnologias (2012), conforme descrito no Quadro 1. 


\begin{tabular}{|c|c|c|c|c|}
\hline Bimestre & 10 & $2^{0}$ & 30 & $4^{0}$ \\
\hline $\begin{array}{c}\text { Eixos de } \\
\text { organização } \\
\text { Anos }\end{array}$ & $\begin{array}{l}\text { Estudo de um } \\
\text { agrupamento } \\
\text { tipológico }\end{array}$ & $\begin{array}{l}\text { Estudo de gêneros } \\
\text { textuais do agrupamento } \\
\text { tipológico estudado no } \\
\text { bimestre anterior }\end{array}$ & \multicolumn{2}{|c|}{$\begin{array}{l}\text { Desenvolvimento de um projeto que } \\
\text { engloba a tipologia e os gêneros } \\
\text { estudados, inserindo-os em uma } \\
\text { esfera discursiva }\end{array}$} \\
\hline $6^{\circ}$ ano & narrar & $\begin{array}{l}\text { crônica narrativa letra de } \\
\text { música }\end{array}$ & discurso artístico & discurso artístico \\
\hline $7^{\circ}$ ano & relatar & $\begin{array}{l}\text { notícia relato de } \\
\text { experiência }\end{array}$ & $\begin{array}{l}\text { discurso } \\
\text { jornalístico }\end{array}$ & $\begin{array}{l}\text { discurso } \\
\text { jornalístico }\end{array}$ \\
\hline $8^{\circ}$ ano & prescrever & \begin{tabular}{|l|} 
anúncio publicitário \\
regras de jogos \\
\end{tabular} & $\begin{array}{l}\text { discurso } \\
\text { publicitário }\end{array}$ & \begin{tabular}{|l|} 
discurso \\
publicitário \\
\end{tabular} \\
\hline $9^{\circ}$ ano & $\begin{array}{l}\text { expor, } \\
\text { argumentar }\end{array}$ & $\begin{array}{l}\text { artigo de opinião carta } \\
\text { do leitor }\end{array}$ & discurso político & discurso político \\
\hline
\end{tabular}

Quadro 1 - Organização do trabalho no Currículo do Estado de São Paulo (SÃO PAULO, 2012).

O Currículo de Língua Portuguesa de São Paulo estrutura-se a partir das tipologias textuais (narrar, relatar, prescrever, expor e argumentar), dos gêneros textuais selecionados, das esferas discursivas (publicitária, jornalística, artística e política) e da história (reflexão sobre valores sociais, políticos, econômicos, culturais etc.) Tais conceitos organizam a progressão dos conteúdos a serem trabalhados em cada um dos bimestres dos quatro anos finais do ensino fundamental. Em todos os anos, no $1^{0}$ bimestre, o eixo principal é o estudo de um agrupamento tipológico (narrar, expor, descrever ações e argumentar, respectivamente, do 60 ao 90 ano). No $2^{\circ}$ bimestre, por sua vez, o trabalho é organizado em torno do estudo de gêneros textuais que apresentem, predominantemente, o agrupamento tipológico estudado no bimestre anterior. Já nos $3^{\circ}$ e $4^{0}$ bimestres, desenvolve-se um projeto que engloba a tipologia e os gêneros estudados, inserindo-os em uma perspectiva discursiva.

Porém, se considerarmos as práticas sociais, as pessoas participam de situações comunicativas de diferentes esferas discursivas, interagindo com textos de variados gêneros e tipos. Estudar um único agrupamento por ano, de uma única esfera discursiva parece orientar-se por uma estratégia didática que não encontra respaldo nas práticas sociais. Há ainda outra ressalva. Como são cinco as tipologias textuais selecionadas e quatro os bimestres, parece excessivo destinar um ano ao estudo do agrupamento da ordem do 
“prescrever” e deslocar a uma posição coadjuvante a ordem do “expor” tão presente no discurso acadêmico.

A implementação desse tipo de organização só é possível a partir da produção de material didático estruturado em conformidade com a proposta. Sem esse material de apoio, seria muito difícil pôr em prática as prescrições do currículo com base, por exemplo, nos livros didáticos aprovados pelo Programa Nacional do Livro Didático (PNLD).

Subjacente a esse tipo de proposta, tão fortemente estruturada, instala-se a crença de que as atividades, uma vez desenvolvidas conforme as orientações curriculares, assegurem o desenvolvimento das habilidades pretendidas. Coerente com a concepção de linguagem assumida, não existe uma aplicação isenta do material didático-pedagógico. Os materiais didáticos também são textos lidos a partir dos saberes prévios de professores e de alunos. Não se garante aprendizagem apenas gerenciando o tempo didático.

Tratamento diferente é dado pelas Diretrizes Curriculares da Educação Básica - Língua Portuguesa do Paraná (2008). Em Língua Portuguesa/Literatura, o “conteúdo estruturante” é o “discurso como prática social”, a partir do qual são escolhidos os conteúdos básicos - os gêneros discursivos conforme as esferas sociais de circulação (PARANÁ, 2008, p. 89-90). Ao final do documento, apresenta-se um quadro adaptado de similar disponível na tese de doutorado de Jaqueline Peixoto Barbosa (Pontifícia Universidade Católica de São Paulo, São Paulo, 2001). 

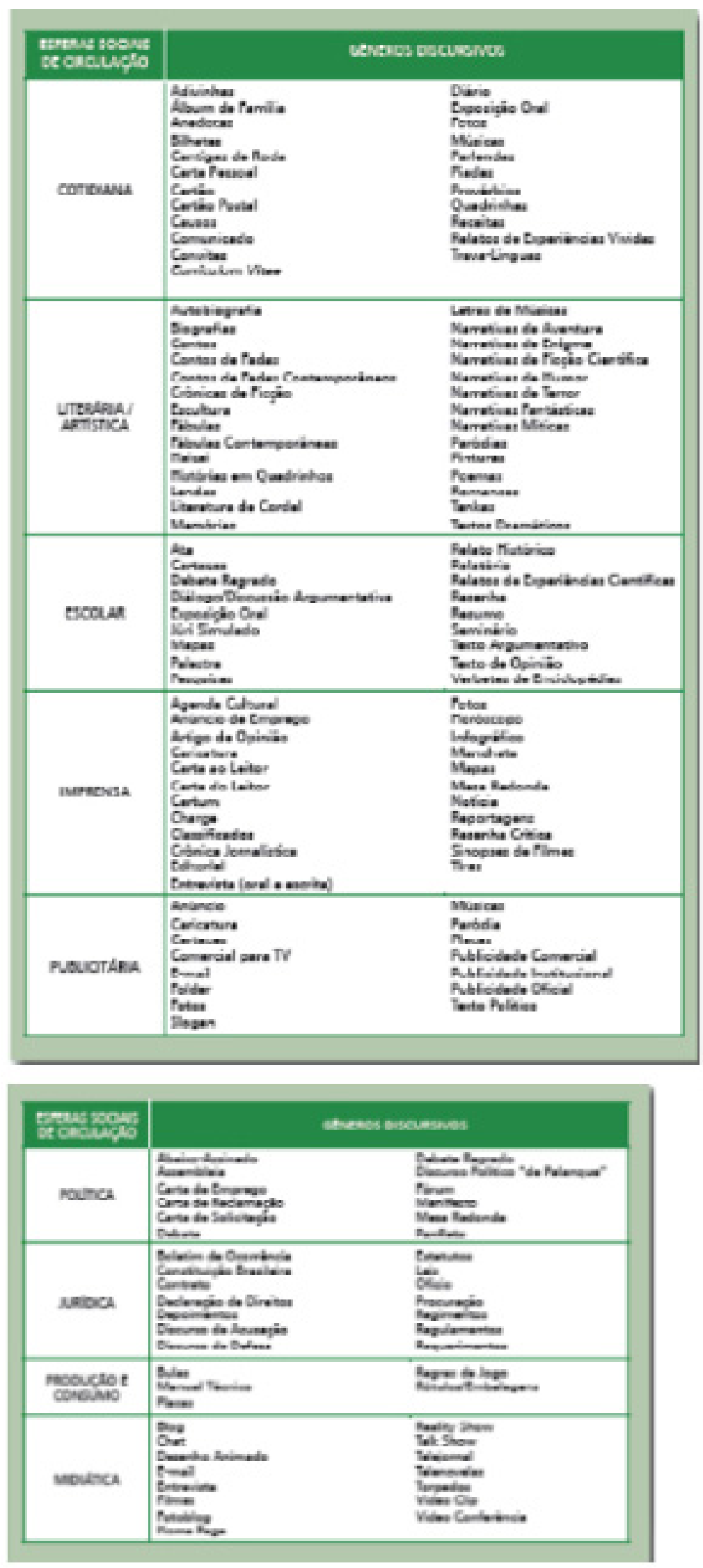

Figura 1 - Tabela de gêneros conforme as esferas de circulação (PARANÁ, 2008, p. 100-101). 
Nos quadros em que se enumeram as capacidades básicas para cada um dos anos do segundo ciclo do ensino fundamental, as Diretrizes Curriculares da Educação Básica - Língua Portuguesa (2008) do Paraná estabelecem a seguinte orientação:

Para o trabalho das práticas de leitura, escrita, oralidade e análise linguística serão adotados como conteúdos básicos os gêneros discursivos conforme suas esferas sociais de circulação. Caberá ao professor fazer a seleção de gêneros, nas diferentes esferas, de acordo com o Projeto Político Pedagógico, com a Proposta Pedagógica Curricular, com o Plano Trabalho Docente, ou seja, em conformidade com as características da escola e com o nível de complexidade adequado a cada uma das séries (PARANÁ, 2008, p. 91, 92, 94 e 96).

Considerando-se o gênero como ferramenta capaz de mobilizar a emergência de diferentes recursos discursivos e linguísticos, a seleção deste ou daquele certamente terá impactos em relação ao que se ensina. Uma vez que a decisão a respeito de quais gêneros priorizar é do professor, o plano de trabalho, como sustenta o documento,

[...] é o lugar da criação pedagógica do professor, onde os conteúdos receberão abordagens contextualizadas histórica, social e politicamente, de modo que façam sentido para os alunos nas diversas realidades regionais, culturais e econômicas, contribuindo com sua formação cidadã (PARANÁ, 2008, p. 89).

Ainda em relação a esse assunto, as Diretrizes Curriculares orientam que os gêneros "precisam ser retomados nas diferentes séries com níveis maiores de complexidade, tendo em vista que a diferença significativa entre as séries está no grau de aprofundamento e da abordagem metodológica” (PARANÁ, 2008, p. 90).

São, portanto, o grau de aprofundamento e a abordagem metodológica os fatores que verdadeiramente orientam a progressão. Formas de aferir esse grau de aprofundamento não são objeto do documento. Quais são as diferentes abordagens metodológicas que implicam aprofundamento no tratamento dos conteúdos também não. Sabe-se, porém, que essa não é uma tarefa simples. Essas diretrizes podem gerar uma diversidade bastante grande de concretizações, o que impede a avaliação em larga escala da existência de equilíbrio na distribuição dos conteúdos.

Do ponto de vista prático, é possível esperar que o livro didático adotado acabe pautando a seleção de gêneros e textos adotados, já que as coleções disponíveis no catálogo do PNLD orientam-se pela diversidade de gêneros, ainda que possam não atender aos princípios defendidos pelas Diretrizes Curriculares da Educação Básica - Língua Portuguesa/PR, 2008. 


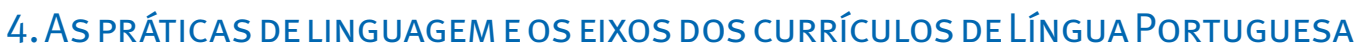

Se já sob a ótica das teorias da comunicação os textos assumiam centralidade no ensino de Língua Portuguesa, é sob as teorias enunciativas e discursivas que a centralidade do texto se adensa, estabelecendo como eixos estruturantes da disciplina escolar as "práticas de linguagem".

Inspirador de um ensino orientado pelos usos da linguagem, 0 texto na sala de aula propõe um ensino centrado em três atividades: a prática de leitura de textos, a prática de produção de textos e a prática de análise linguística. Geraldi não trata as práticas de modo estanque: as três interligam-se por meio do texto.

Ao defenderem que a finalidade do ensino da língua é a produção/recepção de discursos, os Parâmetros Curriculares Nacionais: terceiro e quarto ciclos do ensino fundamental: Língua Portuguesa (1998), explicitamente (nota 14, p. 35) aderem a esse modelo de organização, deixando mais evidente o trabalho não apenas com os textos da modalidade escrita, mas também com os da modalidade oral, conforme representado na Figura 2.

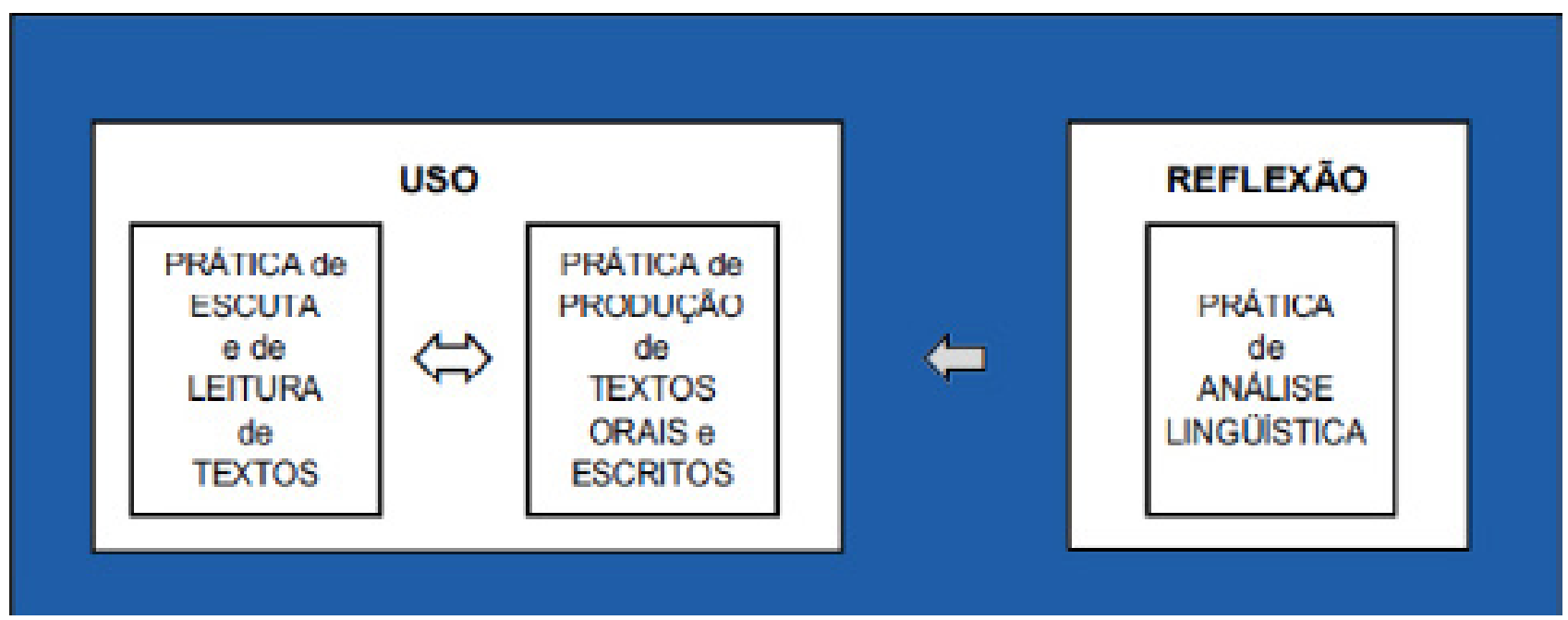

Figura 2 - Eixos organizadores de Língua Portuguesa (BRASIL, 1998, p. 35).

Em linhas gerais, os documentos analisados (AC, AL, MT, PR, PE, SP) consagram esse modelo. Seguem alguns destaques.

a) Acre

As práticas de linguagem que organizam a Orientação Curricular/AC são: Linguagem Oral, Leitura, Procedimentos de estudo de textos expositivos, Análise linguística, Produção de textos escritos, Produção de textos de apoio à fala adequados às necessidades de estudo, Revisão de textos. 
Nessa organização, chamam atenção, além da ênfase ao trabalho com os textos expositivos que circulam na própria esfera escolar - essenciais ao estudo das diferentes áreas de conhecimento -, a extração da revisão do processo de produção textual.

Ainda que os PCN já ressaltassem a importância da linguagem escrita como objeto de ensino nas diferentes áreas, verifica-se, em Língua Portuguesa, um adensamento do assunto. Porém, ao explorar tais conteúdos apenas em Língua Portuguesa, já que apenas em Ciências se encontra um objetivo que atribua à linguagem um estatuto organizador do trabalho, as Orientações Curriculares para o Ensino Fundamental/AC (2010) terminam por conferir um caráter instrumental à linguagem e os resultados obtidos tendem a ser pouco produtivos.

Apesar da importância dada à revisão de textos, ao tratá-la como um eixo independente da "produção de textos escritos", a atividade parece deixar de se constituir como uma das etapas do processo de escritura. Incentivar os alunos a revisitarem os textos que produzem, auxiliá-los a desenvolver os instrumentos que os auxiliem nessa tarefa permite que os estudantes monitorarem todo o processo de produção textual, coordenando os papéis de produtor, leitor e avaliador do seu próprio texto. Essa orientação desloca a ênfase da intervenção do produto final para todo o processo de produção, ou seja, monitora-se a produção ao longo de todo o seu percurso (planejamento, textualização e revisão dos textos) e não somente após a primeira versão.

b) Paraná

Apoiando-se em teorias críticas da educação, as Diretrizes Curriculares da Educação Básica/PR (2008) assumem um currículo disciplinar, baseado nas dimensões científica, artística e filosófica do conhecimento, entendendo que

a função da instituição escolar é especialmente importante para os estudantes das classes menos favorecidas, que têm nela uma oportunidade, algumas vezes a única, de acesso ao mundo letrado, do conhecimento científico, da reflexão filosófica e do contato com a arte

(PARANÁ, 2008, p. 14).

Porém, enfatizam que os conteúdos disciplinares devem ser tratados de modo contextualizado, estabelecendo-se, entre eles, relações interdisciplinares, com a finalidade de "atender igualmente aos sujeitos, seja qual for sua condição social e econômica, seu pertencimento étnico e cultural e às possíveis necessidades especiais para aprendizagem" (PARANÁ, 2008, p. 14). 
A seleção de conteúdos responde aos conteúdos estruturantes da disciplina e aos campos de estudo que as identificam como conhecimento histórico:

Entende-se por conteúdos estruturantes os conhecimentos de grande amplitude, conceitos, teorias ou práticas, que identificam e organizam os campos de estudos de uma disciplina escolar, considerados fundamentais para a compreensão de seu objeto de estudo/ensino (PARANÁ, 2008, p. 25).

Os “conteúdos básicos” que devem ser objeto de ensino-aprendizagem em cada ano envolvem os conteúdos mais estabelecidos e os que emergem do debate contemporâneo. Na disciplina de Língua Portuguesa há apenas um único conteúdo estruturante: “discurso como prática social”. Os conteúdos básicos são os gêneros discursivos nas diferentes práticas de linguagem:

Para o trabalho das Práticas de Leitura, Escrita, Oralidade e Análise Linguística serão adotados como conteúdos básicos os gêneros discursivos conforme suas esferas sociais de circulação (PARANÁ, 2008, p. 91).

c) Pernambuco

Nos Parâmetros Curriculares de Língua Portuguesa para o Ensino Fundamental e Médio/PE (2012), há a proposição de expectativas de aprendizagem para seis eixos:

- Apropriação do sistema alfabético;

- Análise linguística (eixo vertical);

- Oralidade;

- Leitura;

- Letramento literário;

- Escrita.

O documento orienta-se por uma abordagem em espiral dos conhecimentos, assumindo o texto como unidade de ensino e a teoria dos gêneros textuais como organizadora das práticas de linguagem, ainda que sejam as sequências ou tipos textuais o que efetivamente dispõe os eixos de Leitura e de Escrita.

Merece destaque o estatuto conferido ao Sistema de escrita e ao Letramento literário. No primeiro caso, há o enfrentamento dos problemas referentes ao analfabetismo escolar e, no segundo, os textos da esfera literária diferenciamse dos textos das demais esferas discursivas, corrigindo uma tendência de pasteurizar textos ficcionais e não ficcionais.

Embora o documento avance no sentido de propor como eixo o Letramento literário, não se verifica ainda um tratamento diferenciado em relação aos modos de ler das diferentes esferas discursivas (literária, acadêmica, jornalística etc.). Principalmente em relação a esse eixo, teria sido oportuno 
refletir sobre os diferentes modos de ler na escola (leitura compartilhada $x$ leitura autônoma; leitura extensiva x leitura de aprofundamento; obras de livre escolha $x$ obras indicadas pelo professor) e sobre uma proposta de educação literária: o que ler (ficção em prosa x em verso; narrativas longas x narrativas curtas; obras clássicas $x$ contemporâneas; obras integrais $x$ adaptações)?

d) São Paulo

O Currículo do Estado de São Paulo (2012) organiza-se em torno dos seguintes princípios centrais: "a escola que aprende; o currículo como espaço de cultura; as competências como eixo de aprendizagem; a prioridade da competência de leitura e de escrita; a articulação das competências para aprender; e a contextualização no mundo do trabalho" (SÃO PAULO, 2012, p. 12).

O Currículo adota as competências formuladas para o Exame Nacional do Ensino Médio (ENEM, 1998), entendidas como desdobramentos do princípio da competência leitora e escritora.

O Currículo de Língua Portuguesa, especificamente, defende que o centro do trabalho é o texto, sendo assim: "Para o trabalho escolar com textos, torna-se necessário compreender tanto as características estruturais (ou seja, como o texto é feito) como as condições sociais de produção e recepção, para refletir sobre sua adequação e funcionalidade” (SÃO PAULO, 2012, p. 34).

Apoiando-se nesses princípios, o documento apresenta alguns conceitos estruturantes: tipo, gênero, texto, enunciação e discurso. Esses conceitos organizam a progressão dos conteúdos a serem trabalhados em cada um dos bimestres dos quatro anos finais do ensino fundamental:

É preciso destacar ainda que os conteúdos serão apresentados nas séries seguindo outros aspectos organizadores. Um deles é o desenvolvimento das habilidades de leitura, de escrita, de fala, de audição e as relacionadas aos aspectos gramaticais da língua (SÃO

\subsection{As práticas de oralidade}

Os Parâmetros Curriculares Nacionais (1998) tiveram o mérito de conferir à oralidade e aos gêneros orais um lugar de destaque no ensino. As propostas curriculares analisadas ( $A C, A L, M T, P R, P E, S P$ ) seguem essa trilha. Sem ignorar que uma das principais funções da escola é inserir crianças e jovens na cultura escrita, não é pelo fato de os alunos já dominarem de modo eficiente a variedade linguística de sua comunidade de origem quando chegam à escola que não seja possível ampliar sua competência oral, principalmente em 
relação às instâncias públicas que implicam necessidades de compreensão do mundo, interlocutores desconhecidos, mobilização de sistemas de referências nem sempre compartilhados, temáticas mais abstratas e sistematizadas.

Do ponto de vista dos usos, a fala acha-se mais presente que a escrita em nossas atividades cotidianas, apesar de a escrita receber maior avaliação social. É importante destacar que esse valor não se sustenta em parâmetros linguísticos, mas em uma postura ideológica: não há razão alguma para desprestigiar a oralidade e supervalorizar a escrita.

Também não há razão para continuar situando a fala e a escrita em lados opostos. A linguística contemporânea rompe essa visão dicotômica, ou seja, não se admite uma oposição completa entre as duas modalidades. Ademais, os estudos recentes têm evitado o equívoco muito comum de observar a fala na perspectiva da escrita: é essencial analisar a oralidade em suas peculiaridades nos processos de textualização.

Outro tópico importante é o de que a distinção entre a fala e a escrita não se fundamenta apenas no código sonoro e gráfico, mas em uma série de outros aspectos. Habitualmente, a fala se manifesta nas relações face a face e na presença dos interlocutores, embora haja casos em que se interaja oralmente por meios eletrônicos, como por telefone, Skype. Convém não ignorar, portanto, que a realização fônica não é condição suficiente para a produção de fala. Por exemplo, as notícias nas rádios e TVs não são tipicamente orais, apesar de só chegarem ao público na forma fônica: o âncora do telejornal faz uso de teleprompters para auxiliar a leitura de seus textos; os poemas e as letras de música que se sabem de cor não podem ser chamados legitimamente de língua falada: são manifestações de escrita oralizada. Por outro lado, não se deve pensar a escrita como uma simples transposição da fala: nem todas as variações audíveis são conservadas na escrita.

Em relação à textualização, há muitos processos presentes em ambas as modalidades da língua, visando, em princípio, à construção de sentido. Quando falamos ou escrevemos um texto, utilizamos diversas estratégias discursivas para produzi-lo. Fazemos e refazemos os enunciados, retomamos os referentes introduzidos no texto com as mais variadas funções, deixamos transparecer o nosso envolvimento sobre o que estamos falando ou escrevendo. Além disso, as características dos gêneros orais ou escritos do texto que produzimos regulam a seleção dos tópicos tratados, sua organização e os recursos estilísticos empregados. Por exemplo, há gêneros que implicam maior grau de informalidade de uso da língua falada até os gêneros que implicam maior 
grau de formalidade - o mesmo se observa com os gêneros escritos. Tanto a fala quanto a escrita variam em função do interlocutor: o ouvinte e o leitor se inscrevem no texto não apenas no momento da recepção, mas no instante mesmo da produção textual. A interação verbal é uma realidade fundamental da língua.

No trabalho desenvolvido em sala de aula, tanto os gêneros escritos como os orais (principalmente os da esfera pública) devem ser trabalhados sem ignorar que a fala, bem como a escrita, sempre se acham situadas e realizamse em condições particulares como eventos comunicativos.

Apoiando-se principalmente em Marcuschi, os Parâmetros Curriculares de Língua Portuguesa para o Ensino Fundamental e Médio/PE (2012) explicitam expectativas de aprendizagens consistentes para o trabalho como o eixo “oralidade", deixando claros os usos que caracterizam as práticas sociais, rejeitando a visão dicotômica entre a fala e a escrita. Discutem temas contemporâneos, como diferenciar a oralidade de escrita oralizada, além de propor um trabalho com os processos de retextualização.

É importante destacar como as potencialidades dos recursos tecnológicos, com as possibilidades de utilização do computador, da internet (músicas, vídeos do YouTube, sites de busca e comunicadores instantâneos), de filmadoras e gravadores digitais disponíveis em aparelhos celulares abrem novas possibilidades para o ensino sistemático da oralidade. Ao converter os textos em objetos, é possível repertoriar e analisar, além das palavras, outros modos de representação: gestos, posturas, expressões faciais, entonações etc. Como essas possibilidades escapam ao tratamento possível nos livros didáticos impressos, há muito a ser desbravado no trabalho com a oralidade na escola.

\subsection{As práticas de leitura e de produção de textos}

Em praticamente todos os documentos analisados, é no eixo "leitura" que se encontram correlações mais fortes com as avaliações externas nacionais (Saeb, Prova Brasil) e com os sistemas mantidos pelos próprios estados (AC, $\mathrm{PE}, \mathrm{SP})$. Alguns dos "conteúdos" selecionados têm redação muito próxima à encontrada em descritores de matrizes de avaliação em larga escala, como em: "Identifica o efeito de sentido produzido pela exploração de recursos linguísticos" (MATO GROSSO, 2010, p. 57) e "Infere o efeito de humor ou ironia em textos (MATO GROSSO, 2010, p. 58).

A ênfase na compreensão leitora induz a uma leitura intensiva ou vertical que 
envolve releitura do texto, visando a uma descrição de seu funcionamento em detrimento de uma leitura mais extensiva ou horizontal, em que se lê um número amplo de textos, promovendo, por exemplo, a leitura lúdica da obra literária. Esse privilégio conferido à leitura intensiva favorece a seleção de textos de gêneros “curtos” (contos, crônicas, notícias, reportagens, editoriais etc.).

Essa escolha sustenta-se ainda pela articulação com a produção de textos. Em geral, na sequência de atividades planejadas com essa finalidade, os textos lidos assumem caráter modelar em relação ao que se espera que os estudantes redijam. Essa orientação didático-metodológica acaba por conferir à leitura um caráter instrumental: lê-se para identificar as regularidades de um gênero, lê-se para reunir informações para escrever. Esse modelo didático que privilegia a produção de textos em detrimento da leitura encontra apoio teórico em Schneuwly e colaboradores ${ }^{3}$, cujas orientações influenciam fortemente documentos curriculares como o de São Paulo e o de Pernambuco. Textos de gêneros mais “longos” (novelas e romances) não se prestam a esse formato didático e terminam por ser negligenciados.

Nas práticas sociais, em geral, a leitura extensiva é a mais frequente para respondera demandascomoatualizar-se, entreter-seetc. Nas práticas escolares, a leitura intensiva é mais frequente como ler para estudar, para responder a questões etc. Esse descompasso pode criar uma distorção, principalmente para crianças e jovens que dependem da escola para constituírem-se como leitores. O risco é sufocar uma recepção mais subjetiva por parte do aluno, impedindo-o de compartilhar essa experiência, submetendo-a à arbitragem dos pares e à autoridade do texto. Corre-se seriamente o risco de inviabilizar a possibilidade de a escola constituir-se em uma comunidade de leitores.

\subsection{As práticas de análise linguística}

Simplificando, é possível sustentar que há dois grandes modos de organizar os estudos da linguagem: um modo retórico e um modo lógico-gramatical. 0 modo retórico constituiu-se a partir do enfrentamento da linguagem verbal como realidade vivida; o modo lógico-gramatical é produto das abstrações que permitiram tratar a língua como um sistema formal, como uma realidade em si.

No artigo “Unidades básicas do ensino de português”, pode-se sustentar que a série de orientações a respeito da prática de análise linguística proposta por

Referimo-nos, principalmente, ao capítulo 4 - Sequências didáticas para o oral e a escrita: apresentação de um procedimento (p. 95-128), de SCHNEUWLY e colaboradores. 
Geraldi inscreve-se no modo retórico:

a análise linguística que se pretende partirá não do texto "bem escritinho", do bom autor selecionado pelo "fazedor de livros didáticos". Ao contrário, o ensino gramatical somente tem sentido se for para auxiliar o aluno e por isso partirá do texto do aluno;

a preparação das aulas de prática de análise linguística será a própria leitura dos textos produzidos pelos alunos nas aulas de produção de textos;

para cada aula de prática de análise linguística, o professor deverá selecionar apenas um problema; de nada adianta querermos enfrentar todos os problemas que podem acontecer num texto produzido

por nosso aluno;

fundamentalmente, a prática de análise linguística deve se caracterizar pela retomada do texto produzido na aula de produção para reescrevê-lo no aspecto tomado como tema da aula de análise;

o material necessário para as aulas de prática de análise linguística: os cadernos de redações dos alunos, um caderno para anotações, dicionários e gramáticas;

em geral, as atividades serão em pequenos grupos ou em grande grupo;

fundamenta essa prática o princípio "partir do erro para a autocorreção" (GERALDI, 1984, p. 63).

Fica evidente que o corpus é constituído pelos textos dos alunos que devem ser reescritos a partir do "problema" selecionado pelo professor. Como sabemos, uma compreensão equivocada dessas orientações acabou por resultar em aulas que tratavam essencialmente dos aspectos normativos, promovendo uma verdadeira higienização dos textos dos alunos.

No artigo "Construção de um novo modo de ensinar/aprender a língua portuguesa”, Geraldi amplia a análise linguística também para os textos que se dão a ler:

A reflexão linguística, terceira prática apontada, se dá concomitantemente à leitura, quando essa deixa de ser mecânica para se tornar construção de uma compreensão dos sentidos veiculados pelo texto, e à produção de textos, quando essa perde seu caráter artificial de mera tarefa escolar para se tornar momento de expressão da subjetividade de seu autor, satisfazendo necessidades de comunicação a distância ou registrando para outrem e para si próprio suas vivências e compreensões de mundo de que participa (GERALDI, 1996, p. 66).

Essa reorientação permite depreender as regularidades em exemplares de textos do gênero em estudo, tornando observáveis certos usos expressivos que possibilitem ampliar os recursos discursivos e linguísticos dos alunos. A análise linguística de textos bem escritos subsidia a atividade de edição e de revisão, de modo que a nova versão se aproxime cada vez mais dos textos que circulam socialmente, respondendo a finalidades comunicativas similares à materializada em textos orais ou escritos. A ampliação do escopo da análise linguística não rompe com o modo retórico. 
É também o modo retórico que está subentendido nos PCN conforme se depreende de:

A atividade mais importante, pois, é a de criar situações em que os alunos possam operar sobre a própria linguagem, construindo pouco a pouco, no curso dos vários anos de escolaridade, paradigmas próprios da fala de sua comunidade, colocando atenção sobre similaridades, regularidades e diferenças de formas e de usos linguísticos, levantando hipóteses sobre as condições contextuais e estruturais em que se dão. É a partir do que os alunos conseguem intuir nesse trabalho epilinguístico, tanto sobre os textos que produzem como sobre os textos que escutam ou leem, que poderão falar e discutir sobre a linguagem, registrando e organizando essas intuições: uma atividade metalinguística, que envolve a descrição dos aspectos observados por meio da categorização e tratamento sistemático dos diferentes conhecimentos construídos (BRASIL, 1998, p. 28).

Em relação ao tratamento dado à análise linguística nos documentos analisados ( $A C, A L, M T, P R, P E, S P)$, há poucos avanços em relação aos $P C N$ : os conteúdos de análise linguística são tratados como complementares às práticas de leitura, oralidade e produção escrita. Espera-se que os estudantes analisem os fenômenos gramaticais e discursivos que perpassam os usos linguísticos.

Operacionalmente, porém, há alguns problemas nessa decisão. A análise linguística, ao tomar os usos como objeto, exige que o analista se localize em um determinado plano estruturador da linguagem - o discursivo/textual, o lexical, o semântico ou o gramatical, que, por sua vez, se constitui de diferentes níveis hierárquicos, cada qual com sua unidade de análise: sintático (sintagma e sentença), morfológico (morfema, palavra), fonológico (fonema, sílaba). Cada um desses planos caracteriza-se pelo uso de uma terminologia linguística hierarquizada; caracteriza-se, enfim, por uma teoria. Como há grande instabilidade de terminologia 4 , nem sempre é fácil depreender o que deve ser ensinado. Além disso, uma abordagem como essa requer ampla formação linguística nem sempre dominada pelos docentes.

Embora já se possa contar com as primeiras gramáticas que se orientam pela descrição do português brasileiro e que se embasam em teorias linguísticas, falta, além de certa estabilidade terminológica, transposição didática de modo a orientar o planejamento de boas situações didáticas capazes de sustentar a análise crítica dos saberes implicados na descrição gramatical. Assumindo um tom mais propositivo, falta responder às questões: 0 que

Referimo-nos ao estatuto terminológico das unidades lexicais de um sistema linguístico. Não há ainda sistematização dos termos linguísticos de modo a assegurar uma interpretação minimamente estável. A Nomenclatura Gramatical Brasileira (NGB), datada de 1959, não é suficiente para descrever a dimensão discursiva da linguagem. 
deve ser ensinado de modo sistemático? Apenas os conteúdos implicados no modo retórico ou também os implicados no modo lógico-gramatical? Com que finalidade? Como? Quando? Que tratamento dar à metalinguagem? De que maneira é possível administrar a progressão das aprendizagens, articulando-a a uma visão longitudinal dos objetivos de aprendizagem de modo a ampliar efetivamente a competência discursiva dos alunos?

O vácuo deixado pelo não enfrentamento dessas questões, como se sabe, é preenchido pela tradição escolar. Na ausência de forma e conteúdo para o novo, mantém-se a tradição. Basta folhear os livros didáticos destinados aos anos finais do ensino fundamental para constatar que o modo lógicogramatical segue firme e forte.

Merece destaque o tratamento dado à variação linguística que, assumida como um processo inerente à linguagem, deveria permear todo o trabalho, principalmente em relação ao registro. Ainda que os documentos curriculares sejam explícitos em relação ao respeito às variantes dialetais e socioculturais faladas pelos alunos, falta uma orientação mais clara para a descrição dos traços que distinguem o português brasileiro popular do português brasileiro culto, para assim emoldurar o tratamento dado à norma culta.

\section{CONSIDERAÇÕES FINAIS}

É inegável a centralidade da noção de gênero (de texto/de discurso) no âmbito das propostas curriculares, evidenciando a articulação entre fatores linguísticos, associados a diferentes aspectos da organização textual, a fatores situacionais, implicados nas tarefas de produção e de compreensão textuais. Porém, os estudos linguísticos a respeito do assunto podem ter diferentes enquadramentos teórico-epistemológicos (análise do discurso, linguística textual, interacionismo sociodiscursivo, abordagem sistêmicofuncional). Não é propósito deste artigo apontar os aspectos particulares que a noção pode assumir no quadro de cada uma dessas perspectivas teóricas, apenas chamar a atenção a seus impactos no ensino e, particularmente, nos documentos curriculares.

Na literatura a respeito do assunto, admite-se que qualquer texto se relaciona com um gênero, que reproduz de forma mais fiel ou mais livre, porém o gênero só se torna acessível por meio de textos empíricos que se constituem como exemplares do gênero. As formas linguísticas evidenciam, portanto, as relações entre o texto e as situações comunicativas. Os usuários da 
língua, quando falam e escrevem, ouvem e leem, recorrem aos gêneros de que dispõem de forma mais ou menos explícita e consciente: os gêneros funcionam nas situações comunicativas.

Uma linguística dos gêneros de texto constitui-se, assim, também como uma área paradoxal: centrada sobre objetos irredutíveis à dimensão linguística, cabe a ela a tarefa de descrever essa mesma dimensão linguística. O que resulta não é, porém, uma mera face linguística dos textos, obtida por apagamento ou abstração de fatores contextuais. Trata-se antes de chegar à organização linguística dos textos por meio de um percurso descendente que vai das atividades sociais aos gêneros de texto, dos gêneros aos textos empíricos e dos textos às unidades e processos linguísticos que os constituem - na reprodução e/ou na inovação do gênero em causa.

Em Língua Portuguesa, o debate a respeito dos "conteúdos” escolares é complexo por envolver objetivos de aprendizagem que se centram na língua em uso e não apenas nos saberes derivados no âmbito da investigação linguística: a coerência dos "conteúdos" da disciplina não se sustenta com a adoção de uma teoria linguística específica, já que nenhuma consegue explicar o funcionamento global da linguagem.

Ao relacionar os modelos linguísticos e o ensino, há ainda o problema da terminologia. Sabe-se que cada termo corresponde a um conceito que, por sua vez, se integra a uma rede conceitual que precisa ter um mínimo de coerência. Com a multiplicidade de modelos linguísticos (estruturalista, gerativista, sistêmico-funcional), instaura-se uma verdadeira torre de Babel. $O$ fato de as contribuições das ciências da linguagem serem diversas tanto em relação ao objeto quanto em relação aos métodos tem repercussões no ensino. Apesar dos diferentes referenciais teóricos, é necessário dar coerência aos “conteúdos", considerando a necessidade de responder às contribuições das ciências da linguagem, mas sem romper com os usos sociais e com os conhecimentos da comunidade educativa. 


\section{Teaching and Learning Portuguese in the Later Years of Primary Education}

Abstract: This article presents an analysis of curricular documents of the discipline of Portuguese in six Brazilian states ( $A C, A L, M T, P R, P E$, and SP). Initially, it outlines the theoretical foundations that underpin the curricular documents, and then discusses the implications of establishing the text as the teaching unit (which is recurring in the six documents) and the way of treating genres; finally, it reflects about the language practices that set the organization of the contents: orality, reading, text production, and linguistic analysis. The reflections are pervaded by a dialogue with $O$ texto na sala de aula [THE TEXT IN THE CLASSROOM] - a book that is emblematic of the renovation of Portuguese teaching - and the National Curriculum Parameters (1998), both of which can help us find answers to this question: What changes are noticeable in the teaching and learning of Portuguese in the last 30 years?

Keywords: Curriculum, Portuguese, teaching. 


\section{Enseñar y aprender Lengua Portuguesa en los años finales de la enseñanza básica}

Resumen: Portuguesa de seis estados brasileños (Acre, Alagoas, Mato Grosso, Paraná, Pernambuco y São Paulo). Inicialmente, se exponen los fundamentos teóricos que sostienen los documentos curriculares; a continuación, se analizan las implicaciones de asumir el texto como unidad de enseñanza (algo recurrente en los seis documentos) y el tratamiento dado a los géneros textuales; y, por último, se hacen consideraciones sobre las prácticas de lenguaje que estructuran la organización de los contenidos: la oralidad, la lectura, la producción de textos y el análisis lingüístico. Las reflexiones dialogan con el libro O TEXTO NA SALA DE AULA [El texto en el aula] -obra emblemática de la renovación de la enseñanza de Lengua Portuguesa- y con los Parámetros Curriculares Nacionales (1998), directrices del Gobierno brasileño que ayudan a buscar respuestas a la siguiente pregunta: ¿qué cambios son notables en la enseñanza y el aprendizaje de Lengua Portuguesa en los últimos 30 años?

Palabras clave: Currículo. Lengua Portuguesa. Enseñanza. 


\section{REFERÊNCIAS}

ACRE. Orientações Curriculares para o Ensino Fundamental. Caderno 1 Língua Portuguesa. Rio Branco: SEE /AC, 2010.

ALAGOAS. Referencial Curricular da Educação Básica para as escolas públicas de Alagoas. Maceió: Suped/SEE/AL, 2010.

ANTUNES, I. Muito além da gramática: por um ensino de línguas sem pedras no caminho. São Paulo: Parábola, 2007.

BAKHTIN, M. Estética da criação verbal. São Paulo: Martins Fontes, 1997. . Marxismo e filosofia da linguagem. São Paulo: Hucitec, 1992.

BARBOSA, Jaqueline Peixoto. Trabalhando com os gêneros do discurso: uma perspectiva enunciativa para o ensino de língua portuguesa. 2001. Tese (Doutorado) - Linguística Aplicada e Estudos da Linguagem, Pontifícia Universidade Católica de São Paulo, São Paulo, 2001.

BATISTA, A. A. G. et al. Currículos para os anos finais do ensino fundamental: concepções, modos de implantação e usos (relatório final de pesquisa). São Paulo: Cenpec, 2015.

BERNSTEIN, B. A pedagogização do conhecimento: estudos sobre recontextualização. Cadernos de Pesquisa, São Paulo, n. 120, p. 75-110, nov. 2003.

BRASIL. Secretaria de Educação Fundamental. Parâmetros Curriculares Nacionais: terceiro e quarto ciclos do ensino fundamental: Língua Portuguesa/ Secretaria de Educação Fundamental. Brasília: MEC/SEF, 1998.

CASTILHO, A. T. de; ELIAS, V. M. Pequena gramática do português brasileiro. São Paulo: Contexto, 2012.

COSSON, R. Letramento literário: teoria e prática. São Paulo: Contexto, 2006. Círculos de leitura e letramento literário. São Paulo: Contexto, 2014.

FORQUIN, J-C. O currículo entre o relativismo e o universalismo. Educação \& Sociedade, Campinas, ano XXI, n. 73, p. 47-70, dez. 2000.

GERALDI, J. W. (Org.). 0 texto na sala de aula: leitura \& produção. Cascavel: Assoeste, 1984. 
. Linguagem e ensino: exercícios de militância e divulgação. Campinas, Mercado de Letras - ALB, 1996.

. A aula como acontecimento. São Carlos: Pedro e João Editores, 2010.

ILARI, R.; BASSO, R. 0 português da gente: a língua que estudamos, a língua que falamos. São Paulo: Contexto, 2006.

KOCH, I. V.; ELIAS, V. M. Ler e compreender: os sentidos do texto. São Paulo: Contexto, 2006.

. Ler e escrever: estratégias de produção textual. São Paulo: Contexto, 2009.

MARCUSCHI, L. A. Da fala para a escrita: atividades de retextualização. São Paulo: Cortez, 2001.

Produção textual, análise de gêneros e compreensão. São Paulo: Parábola, 2008.

MATO GROSSO. Orientativo 2013: Ciclos de Formação Humana. Cuiabá: Seduc/MT, 2013.

PARANÁ. Diretrizes Curriculares da Educação Básica. Curitiba: Seed/PR, 2008.

. Caderno de expectativas de aprendizagem. Curitiba: Departamento de Educação Básica, 2012.

PERNAMBUCO. Base Curricular Comum para as Redes Públicas de Ensino de Pernambuco: Língua Portuguesa. Recife: SEE, 2008.

Parâmetros para a Educação Básica do Estado de Pernambuco: Parâmetros Curriculares de Língua Portuguesa. Ensino Fundamental e Médio. Recife: SEE, 2012.

ROJO, R.; BARBOSA, J. Hipermodernidade, multiletramentos e gêneros discursivos. São Paulo: Parábola, 2015.

SAMPAIO, M. M. F. et al. Propostas curriculares de estados e municípios brasileiros para o ensino fundamental e médio. In: SEMINÁRIO NACIONAL: CURRÍCULO EM MOVIMENTO - PERSPECTIVAS ATUAIS, 1, 2010, Belo Horizonte. Anais... Belo Horizonte, 2010.

SÃO PAULO. Currículo do Estado de São Paulo: Linguagem, códigos e suas 
tecnologias. 2. ed. São Paulo: Secretaria da Educação, 2012.

SCHNEUWLY, B. et al. Gêneros orais e escritos na escola. Campinas: Mercado de Letras, 2004.

VYGOTSKY, L. S. Pensamento e linguagem. São Paulo: Martins Fontes, 1996. . A formação social da mente. São Paulo: Martins Fontes, 1999.

YOUNG, M. Superando a crise na teoria do currículo: uma abordagem baseada no conhecimento. Cadernos Cenpec, São Paulo, v. 3, n. 2, p. 225-250, jun. 2013.

O futuro da educação em uma sociedade de conhecimento: o argumento radical em defesa de um currículo centrado em disciplinas. Revista Brasileira de Educação, São Paulo, v. 16, n. 48, p. 609-623, set./dez. 2011.

Sobre a autora:

Maria José Nóbrega é mestre em Filologia e Língua Portuguesa pela Faculdade de Filosofia, Letras e Ciências Humanas da Universidade de São Paulo e assessora em programas de formação de professores na Área de Linguagem. mazenobrega@hotmail.com

Recebido em: janeiro de 2016

Aprovado em: abril de 2016 